\title{
D-A conjugated polymers containing substituted thiophene, 1,3,4-oxadiazole and non-conjugation linkers: Synthesis and study of optical and electrochemical properties
}

\author{
PRASHANTH KUMAR K R ${ }^{\mathrm{a}}$, UDAYAKUMAR D ${ }^{\mathrm{a}, *}$, SIJI NARENDRAN N $\mathrm{K}^{\mathrm{b}}$, \\ CHANDRASEKHARAN $\mathrm{K}^{\mathrm{b}}$ and RITU SRIVASTAVA ${ }^{\mathrm{c}}$ \\ a Department of Chemistry, National Institute of Technology Karnataka, Surathkal, \\ P.O. Srinivasnagar 575025 India \\ ${ }^{b}$ Department of Physics, National Institute of Technology Calicut, Kerala, 673601 India \\ c Physics of Energy Harvesting, National Physical Laboratory, New Delhi 110012 India \\ e-mail: udayaravi80@gmail.com; udayakumar@nitk.ac.in
}

MS received 6 September 2014; revised 9 November 2014; accepted 16 November 2015

\begin{abstract}
In this communication, we report synthesis and characterization of new D-A conjugated polymers (P1-P3) consisting of electron-donating (D) 3,4-didodecyloxythiophene, electron-accepting (A) 1,3,4oxadiazole unit and non-conjugation linkers. The conjugated segment in P1-P3 contains only five aromatic rings resulting in short conjugation length, but has an alternate D-A arrangement which significantly enhances the intramolecular charge transfer (ICT) interaction within the segment. As a result, these polymers exhibited low optical band gap in the range 2.51-2.76 eV. Fluorescence emission studies revealed that the polymer thin films emit intense blue light with emission maxima in the wavelength rage $430-480 \mathrm{~nm}$. All three polymers undergo both oxidation and reduction processes under electrochemical conditions. Further, these polymers (P1-P3) exhibit low-lying HOMO and LUMO levels as a result of D-A structure of the conjugated segment. Polymer light-emitting devices were fabricated using these polymers as emissive layer with a device configuration of ITO/ $/ \mathrm{MoO}_{3} /$ polymer/LiF/Al. The test device based on P2 emitted blue light with a low threshold voltage of 5 V. Z-scan studies reveal that the polymers exhibit a strong optical limiting behavior. The value of the nonlinear absorption coefficient $(\beta)$ of polymers is of the order $10^{-11} \mathrm{~m} / \mathrm{W}$ which indicates that these materials may be accomplished for fabricating optical limiters.
\end{abstract}

Keywords. Conjugated polymers; conjugation confinement; blue light-emitting polymers; cyclic voltammetry; nonlinear optics.

\section{Introduction}

A great deal of research work is going on in the field of conjugated polymers due to their fascinating optoelectronic properties. ${ }^{1-3}$ Conjugated polymers containing carbon and heteroatom frameworks with alternate donoracceptor (D-A) architecture along the polymer chain are of great importance for directing material properties towards the desired optoelectronic applications. ${ }^{4}$ In D-A conjugated systems, interaction between a strong electron donor (D) and strong electron acceptor (A) units gives rise to a low band gap energy. ${ }^{5}$ In addition, energy levels of the highest occupied molecular orbital (HOMO) and the lowest unoccupied molecular orbital (LUMO) in these systems could be adjusted as desired by judicious selection of donor and acceptor units. Because of this reason, D-A conjugated polymers are emerging as promising materials for the fabrication of

\footnotetext{
*For correspondence
}

optoelectronic devices, particularly polymer light emitting diodes (PLEDs) and polymer solar cells (PSCs). ${ }^{6}$ Furthermore, the increase in effective $\pi$-electron delocalization in $\mathrm{D}-\mathrm{A}$ polymers results in large third-order nonlinear optical susceptibilities, and hence these polymers are considered also as potential candidates in the area of nonlinear optics. ${ }^{7,8}$ Currently, much attention is devoted towards the development of blue light-emitting polymers, because blue light can be converted to green or red using proper dyes, which means a blue lightemitting device alone is capable of generating all colors. It is known that the optical absorption spectra and the emission color of conjugated polymers are directly connected with their band gap energy. In this regard, D-A conjugated polymers with extended conjugation and low band gap energy absorb light at longer wavelengths (in the UV-Vis region) and hence emit light generally in green to red region, whereas blue emission can be expected only in conjugated molecules or oligomers with shorter conjugation length. But these molecules/ 
oligomers usually exhibit poor processability and longterm resistance towards crystallization, phase separation and other morphological degradations. One possible approach to overcome these problems is to develop polymers containing short conjugated segments interconnected through nonconjugated linkers. Such polymers are expected to retain the electronic properties of the conjugated segment and possess the desired processability and morphological stability associated with higher molecular weight polymers.

In our previous work, we observed that D-A conjugated polymers containing 3,4-dialkoxythiophene, 1,3, 4-oxadiazole and other conjugated linkers emit bluish green or green light. ${ }^{9}$ In conjugated polymers, based on the experimental work with oligomeric models, it can be assumed that, the effective conjugation length of the polymer is not larger than $7-10$ units. ${ }^{10}$ Based on this fact and from the results obtained in our previous work, we thought to interrupt the $\pi$-conjugation in D-A conjugated polymers containing 3,4-dialkoxythiophene and 1,3,4-oxadiazole units by introduction of nonconjugation linkers expecting that the confinement of the $\pi$-conjugation would shift their emission wavelength to blue region. Though a few reports are available in the literature on conjugated polymers containing alternating $\pi$-conjugated chromophore and saturated aliphatic soft block, ${ }^{11-16}$ reports on D-A conjugated polymers containing nonconjugated linker are limited. ${ }^{17,18}$ In view of these facts, three polymers (P1-P3) with welldefined short conjugated length were synthesized and characterized in the present study. The conjugated segment in P1-P3 consists of 3,4-didodecyloxythiophene unit as the electron donor (D) moiety and 1,3,4oxadiazole as the electron acceptor (A) unit. The length of the conjugated segment is the same in polymers P1 and $\mathbf{P 3}$ while it is slightly longer in polymer $\mathbf{P 2}$ as it contains additional phenylenevinylene units. The conjugated segments are connected through different nonconjugated linkers and the chemical structure of the repeating unit in P1-P3 is as shown in Figure 1. In P3, the repeating unit contains also cyanophenylenevinylene units. Cyanophenylenevinylene is one of the important structural units incorporated in a variety of conjugated polymers. The cyanovinylene linkage, when present in conjugation (i.e., when it is part of the conjugated system), generally extends the absorption wavelength of these systems towards red region. Whereas in polymer P3, cyanophenylenevinylene unit is not a part of the conjugated system but is linked through the nonconjugated linker. The length of the conjugated segment in P1-P3 is markedly short which may be comparable with the length of a single repeating unit of fully conjugated polymers (Figure 1). But it is important to note the alternate arrangement of donor and acceptor units in the conjugated segment which significantly enhances the intramolecular charge transfer (ICT) interaction thus leading to an extended absorption or low band gap. Hence, we anticipated that this D-A structure with short conjugated length would facilitate blue emission in these polymers (P1-P3).

\section{Experimental}

\subsection{Materials and methods}

All solvents and other reagents were purchased commercially and used without further purification. 2,2'(3,4-Didodecyloxythiophene-2,5-diyl)bis[5-((4-triphenylphosphonion methyl) phenyl)-1,3,4-oxadiazole]dibromide (2) was synthesized according to the reported procedure $^{9}$ starting from thiodiglycolic acid. 4,4'[Hexane-1,6-diylbis(oxy)]dibenzaldehyde (4) was synthesized following the procedure reported by Yuan et al. ${ }^{13}$

\subsection{Instrumentation}

A Stuart SMP3 melting point apparatus was used for the determination of melting point of the synthesized compounds. ${ }^{1} \mathrm{H}$ NMR spectra were obtained with an AMX $400 \mathrm{MHz}$ NMR spectrometer using TMS as internal reference. Infrared spectra of all intermediate compounds, monomers and polymers were recorded on a Nicolet Avatar 330 FTIR (Thermo Electron Corporation).

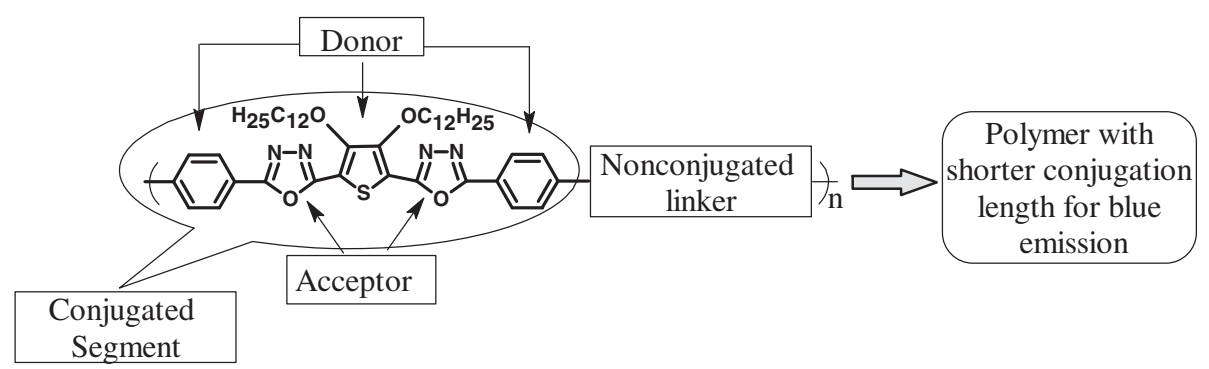

Figure 1. Schematic representation of the arrangement of D and A units in conjugation and the non-conjugated linker in polymers P1-P3. 
Molecular weight of the polymers was determined using an Agilent 1200 gel permeation chromatography system. Thermo gravimetric analysis was carried out using an EXSTAR TG/DTA 7000 (SII Nanotechnology Inc.) thermal analyzer. Differential scanning calorimetry studies were performed using a SHIMADZU DSC60 thermal analyser. Absorption spectra of polymers were recorded using a CINTRA - 101 (GBC scientific equipment) UV-Vis spectrophotometer. Fluorescence spectra were recorded using a JASCO F P2200 spectrofluorimeter. The electrochemical studies of the polymers were carried out using an AUTOLAB PGSTAT 30 electrochemical analyzer. The cyclic voltammograms were recorded using a three-electrode cell system, with a glassy carbon disk as working electrode, a platinum wire as counter electrode and $\mathrm{Ag} / \mathrm{AgCl}$ electrode as the reference electrode. The polymer solution in chloroform was placed on the glassy carbon electrode and the solvent was evaporated to get the polymer coated working electrode. The electrolyte used in the experiment is tetraethylammoniumperchlorate $(0.1 \mathrm{M}$ solution in acetonitrile) and measurements were made at a scan rate of $25 \mathrm{mV} \mathrm{s}^{-1}$. All measurements were calibrated using ferrocene/ferrocenium $\left(\mathrm{Fc} / \mathrm{Fc}^{+}\right)$standard $\left(\mathrm{E}_{\mathrm{FC}}=0.53\right.$ vs. $\mathrm{Ag} / \mathrm{AgCl})$.

\subsection{Fabrication of polymer light-emitting devices}

The polymer light emitting diodes were fabricated with device configuration as $\mathrm{ITO} / \mathrm{MoO}_{3}(5 \mathrm{~nm}) /$ Polymer $(100 \mathrm{~nm}) / \mathrm{LiF}(1 \mathrm{~nm}) / \mathrm{Al}$. ITO(Indium Tin Oxide) coated glass substrates (procured from Vin Karola, USA) having sheet resistance $\sim 20 \Omega / \mathrm{sq}$ were patterned 2 -mmwide ITO lines using laser ablation. Sequentially the patterned ITO substrates were cleaned by ultasonication for 15 min each in acetone, trichloroethylene and iso-propanol solvents and finally dried in vacuum oven. The cleaned ITO substrates were exposed to oxygen plasma for $5 \mathrm{~min}$ to enhance the work function. Thereafter, a thin film (thickness $\sim 5 \mathrm{~nm}$ ) of $\mathrm{MoO}_{3}$ was deposited by thermal deposition onto the ITO substrate. This was followed by spin casting of the emitting layer (P1-P3) (with a thickness of about $100 \mathrm{~nm}$ ) above the $\mathrm{MoO}_{3}$ layer at a speed of $2000 \mathrm{rpm}$ from chlorobenzene solution $(10 \mathrm{mg} / \mathrm{mL})$ filtered through a $0.45 \mu \mathrm{m}$ Teflon filter, followed by vacuum annealing at $120^{\circ} \mathrm{C}$ for $\sim 2 \mathrm{~h}$ in order to remove the organic fraction. Finally, the coated ITO glass plate was transferred to a deposition chamber, where $\mathrm{LiF}$ and $\mathrm{Al}$ cathode layers (with thickness of about 50 and $150 \mathrm{~nm}$, respectively) were vacuum deposited on the polymer layer by thermal evaporation at a pressure of $1 \times 10^{-6}$ Torr. Four pixels, each of active area of $4 \times 4 \mathrm{~mm}^{2}$ are defined per substrate and were used to assess the reproducibility of the device performance. The fabricated devices were finally annealed at $100^{\circ} \mathrm{C}$ in vacuum for 5 min before being characterized. Characterization of the light-emitting device was carried out at room temperature under ambient conditions without protective encapsulation. $I-V$ characteristics of these devices were measured using a Keithley 2400 source meter.

\subsection{Z-scan measurements}

The Z-scan technique ${ }^{19}$ was developed to simultaneously measure the magnitude of both the nonlinear refraction (NLR) and the nonlinear absorption (NLA). In the "open aperture" Z-scan, which provides information about the nonlinear absorption coefficient, a laser beam is used for molecular excitation and its propagation direction is taken as the $\mathrm{z}$-axis. The beam is focused using a convex lens and the focal point is taken as $\mathrm{z}=$ 0 . The beam has maximum energy density at the focus, and the energy density drops symmetrically on either side of the focus (i.e., for positive and negative values of z). In the experiment, the sample is placed in the beam at different positions with respect to the focus (different values of $\mathrm{z}$ ), and the corresponding transmission is measured. The sample sees different laser intensity at each position and therefore the position-dependent transmission will give information on its intensity-dependent transmission as well. The nonlinear absorption coefficient can be calculated from this nonlinear transmission information. The sample was placed in a $1 \mathrm{~mm}$ cuvette. The transmission of the sample at each point was measured using two pyroelectric energy probes (Rj7620, Laser Probe Inc). One energy probe monitored the input energy while the other monitored the energy transmitted through the sample. The second harmonic output (532 nm) of a Q-switched Nd:YAG laser (Quanta Ray, Spectra Physics) was used to excite the molecules. The temporal width (FWHM) of the laser pulses was 7 ns. Laser pulse energy of $25 \mu \mathrm{J}$ was used for the experiments. The pulses were fired in the 'single shot' mode, allowing sufficient time between successive pulses to avoid accumulative thermal effects in the sample.

\subsection{Synthesis}

2.5a Synthesis of monomer $M$ and compounds 1 and 2: These compounds were prepared following the reported procedure. ${ }^{9}$

5,5'-(3,4-bis(dodecyloxy)thiophene-2,5-diyl)bis(2-ptolyl-1,3,4-oxadiazole) (M): ${ }^{1} \mathrm{H}$ NMR (400 MHz, 
$\left.\mathrm{CDCl}_{3}\right) \delta: 8.01(\mathrm{~d}, 4 \mathrm{H}, \mathrm{Ar}), 7.34$ (d, 4H, Ar), 4.31 (t, $\left.4 \mathrm{H},-\mathrm{OCH}_{2}\right), 2.45\left(\mathrm{~s}, 6 \mathrm{H}, \mathrm{Ar}-\mathrm{CH}_{3}\right), 1.91-1.25(\mathrm{~m}, 40 \mathrm{H}$, $\left.-\left(\mathrm{CH}_{2}\right)_{10^{-}}\right), 0.87(\mathrm{t}, 6 \mathrm{H})$. FTIR $\left(\mathrm{cm}^{-1}\right): 2914$ and 2848 $(-\mathrm{C}-\mathrm{H}), 1556(\mathrm{C}=\mathrm{N}), 1481,1464,1350,1051,958$. Element. Anal. Calcd. (\%) For $\mathrm{C}_{46} \mathrm{H}_{64} \mathrm{~N}_{4} \mathrm{O}_{4} \mathrm{~S}$ : Calcd. C 71.83, H 8.39, N 7.29, S 4.16; Found C 71.85, H 8.36, N 7.30, S 4.18.

2,2'-(3,4-didodecyloxythiophene-2,5-diyl)bis[5-(4-bromomethylphenyl)-1,3,4-oxadiazole] (1): ${ }^{1} \mathrm{H} \quad \mathrm{NMR}$ $\left(400 \mathrm{MHz}, \mathrm{CDCl}_{3}\right), \delta(\mathrm{ppm}): 8.15$ (d, 4H, Ar), 7.54 (d, 4H, Ar), 4.59 (s, 4H, Ar- $\left.\mathrm{CH}_{2}-\mathrm{Br}\right), 4.28$ (t, 4H, $\left.-\mathrm{OCH}_{2}-\right), 1.88\left(\mathrm{~m}, 4 \mathrm{H},-\mathrm{O}-\mathrm{C}-\mathrm{CH}_{2}-\right)$ 1.56-1.25 (m, $\left.36 \mathrm{H},\left(-\mathrm{CH}_{2}\right)_{9}-\right), 0.87\left(\mathrm{t}, 6 \mathrm{H},-\mathrm{CH}_{3}\right)$. FTIR $\left(\mathrm{cm}^{-1}\right)$ : 2925, 2841(-C-H), $1589(>\mathrm{C}=\mathrm{N}), 1512,1452,1359$, 1215, 1055, 959, 811, 729. Element. Anal. Calcd. (\%) For $\mathrm{C}_{46} \mathrm{H}_{62} \mathrm{Br}_{2} \mathrm{~N}_{4} \mathrm{O}_{4} \mathrm{~S}$ : Calcd. C 59.59, H 6.75, N 6.05, S 3.45; Found C 59.56, H 6.74, N 6.10, S 3.42.

2,2'-(3,4-didodecyloxythiophene-2,5-diyl)bis[5-((4-triphenylphosphonion methyl)phenyl)-1,3,4-oxadiazole] dibromide (2): $\quad{ }^{1} \mathrm{H} \mathrm{NMR}\left(400 \mathrm{MHz}, \mathrm{CDCl}_{3}\right), \delta(\mathrm{ppm})$ : 7.89-7.23 (m, 38H, Ar), 6.1 (s, 4H, Ar- $\mathrm{CH}_{2}-$ ), 4.31$4.28\left(\mathrm{t}, 4 \mathrm{H},-\mathrm{OCH}_{2}-\right), 1.88-1.25\left(\mathrm{~m}, 40 \mathrm{H},\left(-\mathrm{CH}_{2}\right)_{10}-\right)$, $0.88\left(\mathrm{t}, 6 \mathrm{H},-\mathrm{CH}_{3}\right)$. FTIR $\left(\mathrm{cm}^{-1}\right): 2920,2845$, $1585(>\mathrm{C}=\mathrm{N}), 1486,1429,1366,1101,1056$, 855, 712, 689, 509. Element. Anal. Calcd. (\%) For $\mathrm{C}_{82} \mathrm{H}_{92} \mathrm{Br}_{2} \mathrm{~N}_{4} \mathrm{O}_{4} \mathrm{P}_{2} \mathrm{~S}$ : Calcd. C 67.84, H 6.39, N 3.86, S 2.20; Found C 67.

2.3.2 4,4'-[Hexane-1,6-diylbis(oxy)]dibenzaldehyde $(4)^{11}$ : White solid. ${ }^{1} \mathrm{H}$ NMR (400 $\left.\mathrm{MHz}, \mathrm{CDCl}_{3}\right), \delta$ (ppm): 9.9 (s, 2H, -CHO), 7.82 (d, 4H, Ar), 7.00 (d, $4 \mathrm{H}, \mathrm{Ar}), 4.12\left(\mathrm{t}, 4 \mathrm{H},-\mathrm{O}-\mathrm{CH}_{2}-\right), 1.8-1.6(\mathrm{~m}, 8 \mathrm{H}$, $\left.\left(-\mathrm{CH}_{2}\right)_{4}-\right)$. FTIR $\left(\mathrm{cm}^{-1}\right): 1686(>\mathrm{C}=\mathrm{O}), 2945,2847$ (alkyl C-H), 2847, 1007, 800, 638, 513.

2.5b Synthesis of monomer 3: A mixture of compound 1 ( $2 \mathrm{~g}, 2 \mathrm{mmol})$, 4-hydroxy benzaldehyde ( 0.5 $\mathrm{g}, 4.7 \mathrm{mmol}), \mathrm{K}_{2} \mathrm{CO}_{3}(2 \mathrm{~g}, 1.4 \mathrm{mmol})$ and tetra-n-butyl ammonium bromide $(0.2 \mathrm{~g}, 0.62 \mathrm{mmol})$ in DMF $(20$ $\mathrm{mL}$ ) was heated at $90^{\circ} \mathrm{C}$ for $8 \mathrm{~h}$ and progress of the reaction was monitored by TLC. After the completion of the reaction, the mixture was poured into water under stirring to obtain a precipitate. The precipitate was filtered, washed with methanol and dried. Yield: $80 \%$, Pale yellow solid. M.p.: $156^{\circ} \mathrm{C} .{ }^{1} \mathrm{H}$ NMR (400 $\mathrm{MHz}, \mathrm{CDCl}_{3}$ ), $\delta(\mathrm{ppm}): 9.9$ (S, Ar-CHO), 8.2 (d, 4H, Ar), 7.9 (d, 4H, Ar), $7.6(\mathrm{~d}, 4 \mathrm{H}, \mathrm{Ar}), 7.1(\mathrm{~d}, 4 \mathrm{H}, \mathrm{Ar}), 5.25$ (s, $4 \mathrm{H},-\mathrm{O}-\mathrm{CH}_{2}-\mathrm{Ar}$ ), 4.32 (t, $4 \mathrm{H},-\mathrm{O}-\mathrm{CH}_{2}$ ), $1.25-1.9$ (m, $\left.40 \mathrm{H},\left(-\mathrm{CH}_{2}\right)_{10}\right), 0.88\left(\mathrm{t}, 6 \mathrm{H},-\mathrm{CH}_{3}\right)$. FTIR $\left(\mathrm{cm}^{-1}\right): 1693$ $(\mathrm{C}=\mathrm{O}), 2922,2852,1583(>\mathrm{C}=\mathrm{N}), 1500,1451,1340$,
1231, 1055, 951, 808, 714. Element. Anal. Calcd. For $\mathrm{C}_{6} \mathrm{H}_{72} \mathrm{~N}_{4} \mathrm{O}_{8} \mathrm{~S}$ (\%): Calcd. C 71.41, H 7.19, N 5.55, O 12.68, S 3.17. Found: C 71.45, H 7.14, N 5.50, O 12.62, S 3.11 .

\subsection{Synthesis of polymers}

2.6a Synthesis of polymer P1: To a solution of compound 1 ( $1 \mathrm{~g}, 1.1 \mathrm{mmol})$ in $\mathrm{DMF}(10 \mathrm{~mL})$, 4hydroxyphenol $(0.13 \mathrm{~g}, 1.1 \mathrm{mmol})$ and $\mathrm{K}_{2} \mathrm{CO}_{3}(0.76$ $\mathrm{g}, 6 \mathrm{mmol}$ ) were added and the resulting mixture was heated at $90^{\circ} \mathrm{C}$ for about $9 \mathrm{~h}$ under inert atmosphere. Completion of the reaction was confirmed by TLC, then the reaction mass was poured into a beaker containing distilled water. A few drops of concentrated $\mathrm{HCl}$ were added under stirring to get a precipitate. The obtained precipitate was filtered, washed with excess of water and then dried under vacuum to get polymer P1. Yield: $80 \%$. Orange powder. M.p.: $>300^{\circ} \mathrm{C},{ }^{1} \mathrm{H}$ NMR $(400$ $\mathrm{MHz} \mathrm{CDCl}_{3}$ ), $\delta$ (ppm): 6.9-8.2 (m, 12H, Ar), 5.11(s, $4 \mathrm{H},-\mathrm{Ar}-\mathrm{CH}_{2}-\mathrm{O}-$ ), 4.31 (t, $\left.4 \mathrm{H},-\mathrm{CH}_{2}-\mathrm{O}-\right), 1.24-1.88$ (m, $\left.40 \mathrm{H},\left(-\mathrm{CH}_{2}\right)_{10}\right), 0.86\left(\mathrm{t}, 6 \mathrm{H},-\mathrm{CH}_{3}\right)$. FTIR $\left(\mathrm{cm}^{-1}\right): 2924$, $2852(-\mathrm{C}-\mathrm{H}), 2372,1585(-\mathrm{C}=\mathrm{N}-), 1497,1377,1278$, 1230, 1049, 960, 825, 731 .

2.6b Synthesis of polymer P2: In a round bottom flask, a mixture of compound $2(1.4 \mathrm{~g}, 1 \mathrm{mmol})$, compound $4(1.1 \mathrm{~g}, 1 \mathrm{mmol})$, ethanol $(15 \mathrm{~mL})$ and chloroform $(5 \mathrm{~mL})$ was stirred under nitrogen atmosphere. To the resultant clear solution, sodium ethoxide $(0.33 \mathrm{~g}$, $4.8 \mathrm{mmol})$ in ethanol $(10 \mathrm{~mL})$ was added dropwise at room temperature. After stirring for $10 \mathrm{~h}$, ethanol (10 $\mathrm{mL}$ ) was added to the resulting solution and stirred for $1 \mathrm{~h}$. The obtained polymer $\mathbf{P 2}$ was filtered and washed well with ethanol followed by ethyl acetate and dried under vacuum. Yield: $55 \%$. Bright yellow solid. M.p.: $>300{ }^{0} \mathrm{C},{ }^{1} \mathrm{H}$ NMR $\left(400 \mathrm{MHz}, \mathrm{CDCl}_{3}\right), \delta(\mathrm{ppm}): 7.8-$ $8.1(\mathrm{~m}, 8 \mathrm{H}, \mathrm{Ar}), 7.6$ (d, 4H, -Ar-CH=CH-Ar-), 6.6-7.5 (m, 8H, Ar), 4.31 (t, 4H, - $\left.\mathrm{CH}_{2}-\mathrm{O}-\right)$, 4.0 (t, 4H, Ph-O$\left.\mathrm{CH}_{2}-\right), 1.24-1.86\left(\mathrm{~m}, 48 \mathrm{H},\left(-\mathrm{CH}_{2}\right)_{10}\right.$ and $\left.\left(-\mathrm{CH}_{2}\right)_{4}\right), 0.86$ $\left(\mathrm{t}, 6 \mathrm{H},-\mathrm{CH}_{3}\right)$. FTIR $\left(\mathrm{cm}^{-1}\right): 2922,2851(-\mathrm{C}-\mathrm{H}), 1691$ $(-\mathrm{C}=\mathrm{N}-), 1490,1379,1250,1175,1038,959,833$, 675.

2.6c Synthesis of polymer P3: In a round bottom flask, a mixture of compound $3(1.5 \mathrm{~g}, 1.5 \mathrm{mmol})$ and 1,4-phenylenediacetonitrile $(0.25 \mathrm{~g}, 1.6 \mathrm{mmol})$ was taken in a solvent mixture of ethanol $(15 \mathrm{~mL})$ and chloroform $(5 \mathrm{~mL})$. To this clear solution, sodium ethoxide $(0.16 \mathrm{~g}, 7 \mathrm{mmol})$ in ethanol $(10 \mathrm{~mL})$ was added drop wise with stirring at room temperature under nitrogen atmosphere and the reaction mixture was stirred for 
$20 \mathrm{~h}$. Then, ethanol $(30 \mathrm{~mL})$ was added to the reaction mass, the solid separated was filtered and washed with ethyl acetate. The solid compound thus obtained was taken in a RB flask, ethyl acetate $(10 \mathrm{~mL})$ was added and the contents were stirred for about $20 \mathrm{~h}$ followed by sonication for about $30 \mathrm{~min}$. The reaction mass was then filtered and washed well with ethyl acetate. The solid compound was dried to get the polymer as yellow solid. Yield: $85 \%$, M.p.: $>300^{\circ} \mathrm{C},{ }^{1} \mathrm{H}$ NMR $(400 \mathrm{MHz}$, $\left.\mathrm{CDCl}_{3}\right), \delta$ (ppm): 7.1-8.2 (m, 22H, Ar and $\left.-\mathrm{C}=\mathrm{CH}-\right)$, 5.25 (s, 4H, - Ar- $\left.\mathrm{CH}_{2}-\mathrm{O}-\right), 4.24$ (t, $\left.4 \mathrm{H},-\mathrm{OCH}_{2}-\right), 1.2-$ $1.92\left(\mathrm{~m}, 40 \mathrm{H},\left(-\mathrm{CH}_{2}\right)_{10}-\right), 0.88-0.91\left(\mathrm{t}, 6 \mathrm{H},-\mathrm{CH}_{3}\right)$. FTIR $\left(\mathrm{cm}^{-1}\right)$ : 2924, $2853(-\mathrm{C}-\mathrm{H}), 1655(-\mathrm{C}=\mathrm{N}-)$, 2212 (-CN), 1597, 1423, 1379, 1255, 1178, 1018, 958, $829,611$.

\section{Results and Discussion}

\subsection{Synthesis of monomers and polymers}

Synthetic routes of monomers and polymers are outlined in Figure 2. 2,2'-(3,4-didodecyloxythiophene-2,5diyl)bis[5-(4-bromomethylphenyl)-1,3,4-oxadiazole] (1) was treated with triphenyl phosphine in the presence of DMF to get the required compound, 2,2'-(3,4-didode- cyloxythiophene-2,5-diyl)bis[5-((4-triphenylphosphonionmethyl)phenyl)-1,3,4-oxadiazole]dibromide (2). Alkylation reaction was carried out between compound 1 and 4-hydroxy benzaldehyde to yield monomer 3 . Polymerization reaction was carried out between com pound 1 and 4-hydroxyphenol to yield polymer P1. Wittig reaction was performed between compound 2 and 4,4'-[hexane-1,6-diylbis(oxy)]dibenzaldehyde (4) to obtain polymer $\mathbf{P 2}$ whereas polymer $\mathbf{P 3}$ was synthesized by a reaction between dialdehyde 3 with 1,4phenylenediacetonitrile in presence of sodium ethoxide using a Knoevenagel condensation methodology.

\subsection{Structural characterization}

The structure of synthesized compounds and the polymers was confirmed by their spectral analysis. The ${ }^{1} \mathrm{H}$ NMR spectrum of compound 3 showed singlets at $\delta$ 4.95 and $\delta 9.9 \mathrm{ppm}$ due to methylenoxy ( $\mathrm{Ar}-\mathrm{CH}_{2}-\mathrm{O}-$ $\mathrm{Ar}$ ) and aldehyde protons respectively. In addition, four distinct doublets appeared in the aromatic region. The peaks at $\delta 8.2$ and $7.9 \mathrm{ppm}$ correspond to ortho and meta protons (ortho and meta positions with respect to -CHO group), respectively, of the terminal phenyl ring. Whereas, the doublets at $\delta 7.6$ and $7.1 \mathrm{ppm}$ are
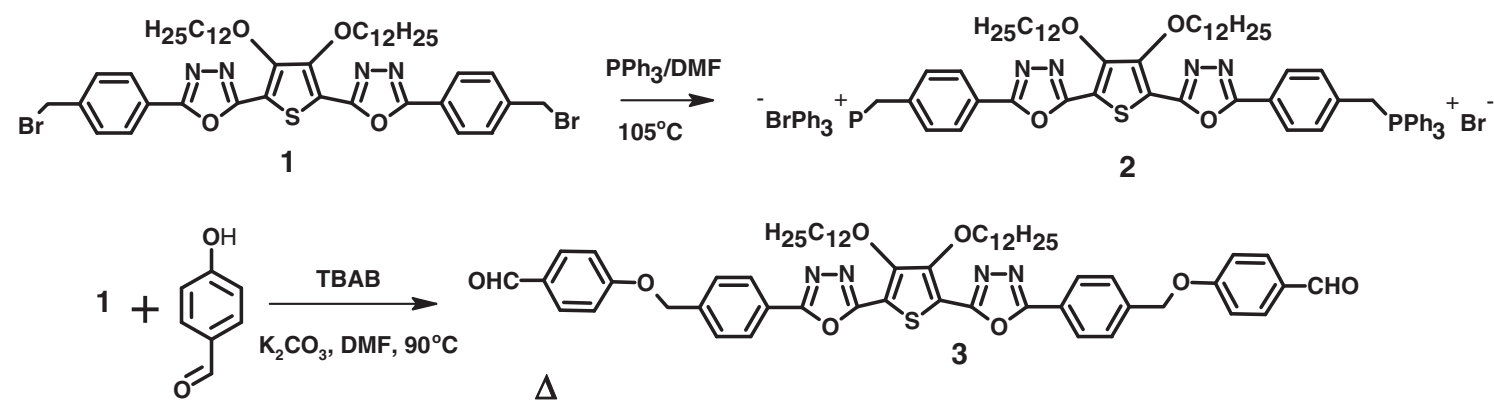

$\Delta$
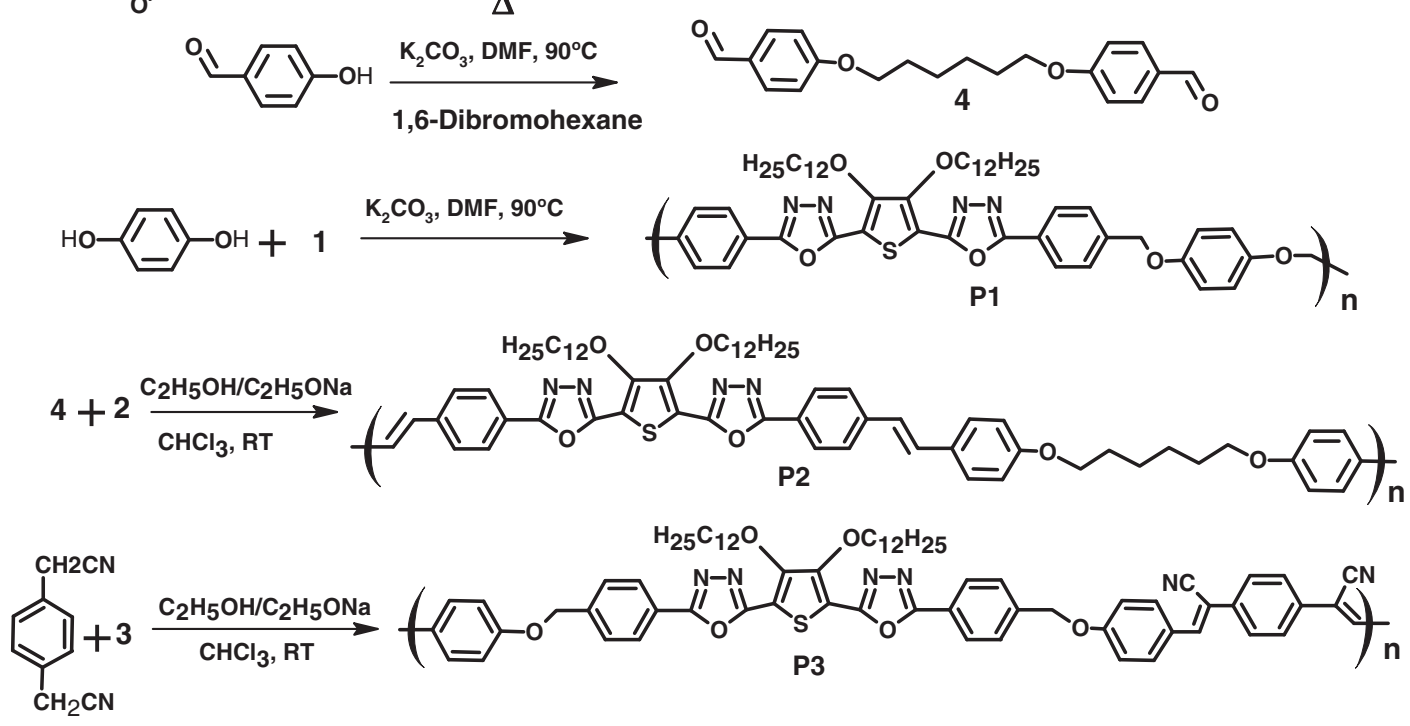

Figure 2. Synthesis of intermediate compounds and polymers (P1, P2 and P3). 
due to ortho and meta protons of the phenyl ring connected to 1,3,4-oxadiazole unit. Further, FTIR spectrum of compound 3 showed a peak at $1693 \mathrm{~cm}^{-1}$ which corresponds to the $-\mathrm{C}=\mathrm{O}$ stretching of aldehyde group. The successful reaction between Wittig salt (2) and 4hydroxy benzaldehyde with the formation of polymer P1 was evident by the absence of a singlet $\delta 4.54 \mathrm{ppm}$ (due to $\mathrm{CH}_{2}-\mathrm{PPh}_{3}$ group) and appearance of a singlet at $\delta 5.11 \mathrm{ppm}$ (due to - $\mathrm{Ar}-\mathrm{CH}_{2}-\mathrm{O}-\mathrm{Ar}$-) in the ${ }^{1} \mathrm{H} \mathrm{NMR}$ spectrum of $\mathbf{P 1}$. The ${ }^{1} \mathrm{H}$ NMR spectrum of polymer $\mathbf{P 2}$ displayed a peak at $\delta 7.6 \mathrm{ppm}$ due to protons of alkene group thus confirming the successful Wittig condensation between compounds 2 and 4. Similarly, the ${ }^{1} \mathrm{H}$ NMR spectrum of polymer $\mathbf{P 3}$ showed a peak at $\delta 7.9$ ppm due to the cyano substituted alkene group along with other characteristic peaks. The spectral characterization data of the intermediate compound and polymers are given in the experimental part. All three polymers (P1, P2 and P3) are soluble in common organic solvents like chloroform, methylene dichloride, tetrahydrofuran, chlorobenzene, DMF, DMSO, etc., at room temperature, which could be due to the presence of long dodecyloxy groups at 3- and 4- positions of the thiophene ring. Molecular weight of the polymers was determined by gel permeation chromatography using THF as

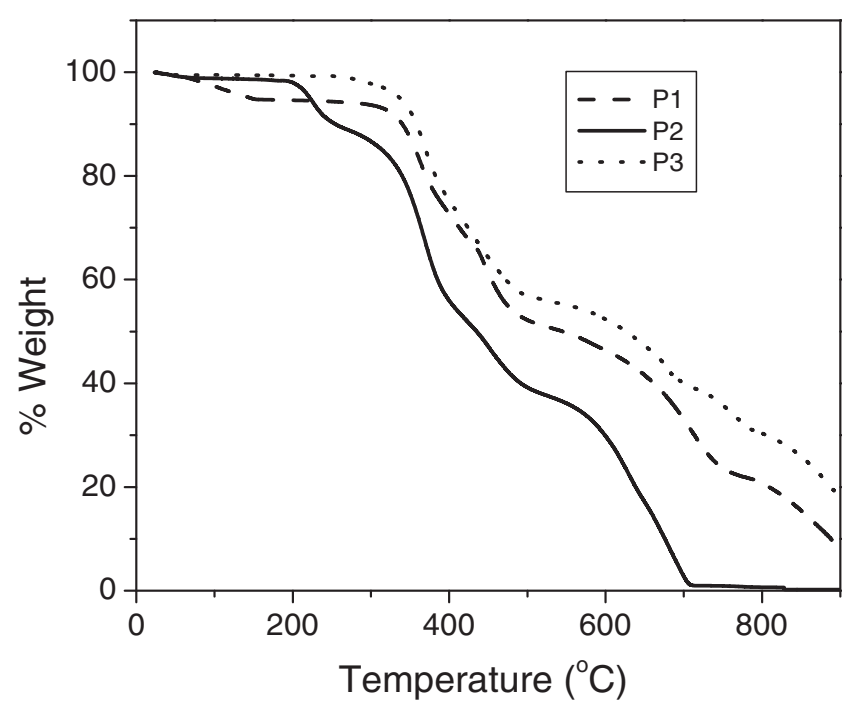

Figure 3. TGA graphs of P1, P2 and P3. eluent against polystyrene standards. The number average molecular weight $\left(\mathrm{M}_{\mathrm{n}}\right)$ of the polymers was found to be 6717 for P1, 21199 for $\mathbf{P 2}$ and 24877 for $\mathbf{P 3}$ with polydispersity (PD) of 1.62, 1.03 and 1.05 for P1, P2 and $\mathrm{P} 3$, respectively.

\subsection{Thermogravimetric analysis}

Thermogravimetric analysis (TGA) curves of polymers P1, P2 and P3 are as shown in Figure 3. The analysis was carried out under nitrogen atmosphere at a heating rate of $5^{\circ} \mathrm{C} / \mathrm{min}$. These polymers exhibit good thermal stability with onset decomposition temperature of $324^{\circ} \mathrm{C}, 204^{\circ} \mathrm{C}$ and $330^{\circ} \mathrm{C}$. respectively for $\mathbf{P 1}, \mathbf{P 2}$ and P3. Among three polymers, P2 showed lower onset decomposition temperature because of the presence of alkoxy (hexyloxy) group along the polymer chain which decomposes at a lower temperature as compared to the methyleneoxy phenyl group present in other two polymers. The initial weight loss to about $5 \%$ below $110^{\circ} \mathrm{C}$ in case of polymer P1 could be due to the loss of trapped moisture or solvent or trace amount of monomer impurity. Differential scanning calorimetry (DSC) studies were performed to observe glass transition temperature $\left(\mathrm{T}_{\mathrm{g}}\right)$ of the polymers. The samples were heated up to $320^{\circ} \mathrm{C}$ under nitrogen atmosphere at a heating rate of $5^{\circ} \mathrm{C} / \mathrm{min}$. No $\mathrm{T}_{\mathrm{g}}$ or melting point was observed suggesting that the polymers are either having very high $\mathrm{T}_{\mathrm{g}}$ or are highly crystalline in nature and decompose before melting.

\subsection{Linear optical properties}

The UV-Vis absorption and fluorescence emission spectral studies were utilized to investigate photophysical properties of $\mathbf{P 1}, \mathbf{P 2}$ and $\mathbf{P 3}$ in dilute $\mathrm{CHCl}_{3}$ solution. Table 1 lists out the optical absorption and emission features for the polymers. This set of data allows for establishment of clear structure-property relationships which typically depend on conjugated $\pi$-systems present in thse polymers. The absorption spectra of polymers in solution (Figure 4a) show maxima at 360, 430 and $380 \mathrm{~nm}$ for P1, P2 and P3. respectively, which

Table 1. Linear optical characterization data of monomer M and polymers P1-P3.

\begin{tabular}{|c|c|c|c|c|c|c|}
\hline \multirow[b]{2}{*}{ Polymer } & \multicolumn{2}{|c|}{ Absorption maxima } & \multicolumn{2}{|c|}{ Emission maxima } & \multirow{2}{*}{$\begin{array}{l}\text { Absorption edge } \\
\quad \text { film (nm) }\end{array}$} & \multirow{2}{*}{$\begin{array}{l}\text { Optical band } \\
\text { gap E } E_{\mathrm{g}}^{\text {opt }}(\mathrm{eV})\end{array}$} \\
\hline & solution $(\mathrm{nm})$ & film (nm) & solution $(\mathrm{nm})$ & film (nm) & & \\
\hline P1 & 360 & 365 & 425 & 434 & 454 & 2.73 \\
\hline P2 & 430 & 437 & 460 & 479 & 494 & 2.51 \\
\hline P3 & 380 & 387 & 454 & 465 & 449 & 2.76 \\
\hline M & 355 & - & 422 & - & - & - \\
\hline
\end{tabular}


signify $\pi \rightarrow \pi^{*}$ transition in the polymers. The corresponding spectra of polymer films (Figure $4 b$ ) did not show appreciable shift in the absorption maxima which implies that there is no much difference in the conformations of the polymer in the two states. Fully conjugated systems generally show a red shift in the absorption maxima in the film state when compared with that of the solution state due to increased extent of the $\pi$-stacking in the film state. Such an effect is limited in P1-P3 because the interruption of the conjugation along the polymer chain by non-conjugate linkers decreases the interchain interactions in these polymers. Further, the long alkoxy pendants on the thiophene ring may also push apart any two adjacent polymer chains thus decreasing the extent of the $\pi$-stacking. A red shift in the absorption maximum was observed for $\mathbf{P} 2$ when compared with those of $\mathbf{P 1}$ and $\mathbf{P 3}$. This could be due to the presence of additional conjugated units (phenylvinyl) in
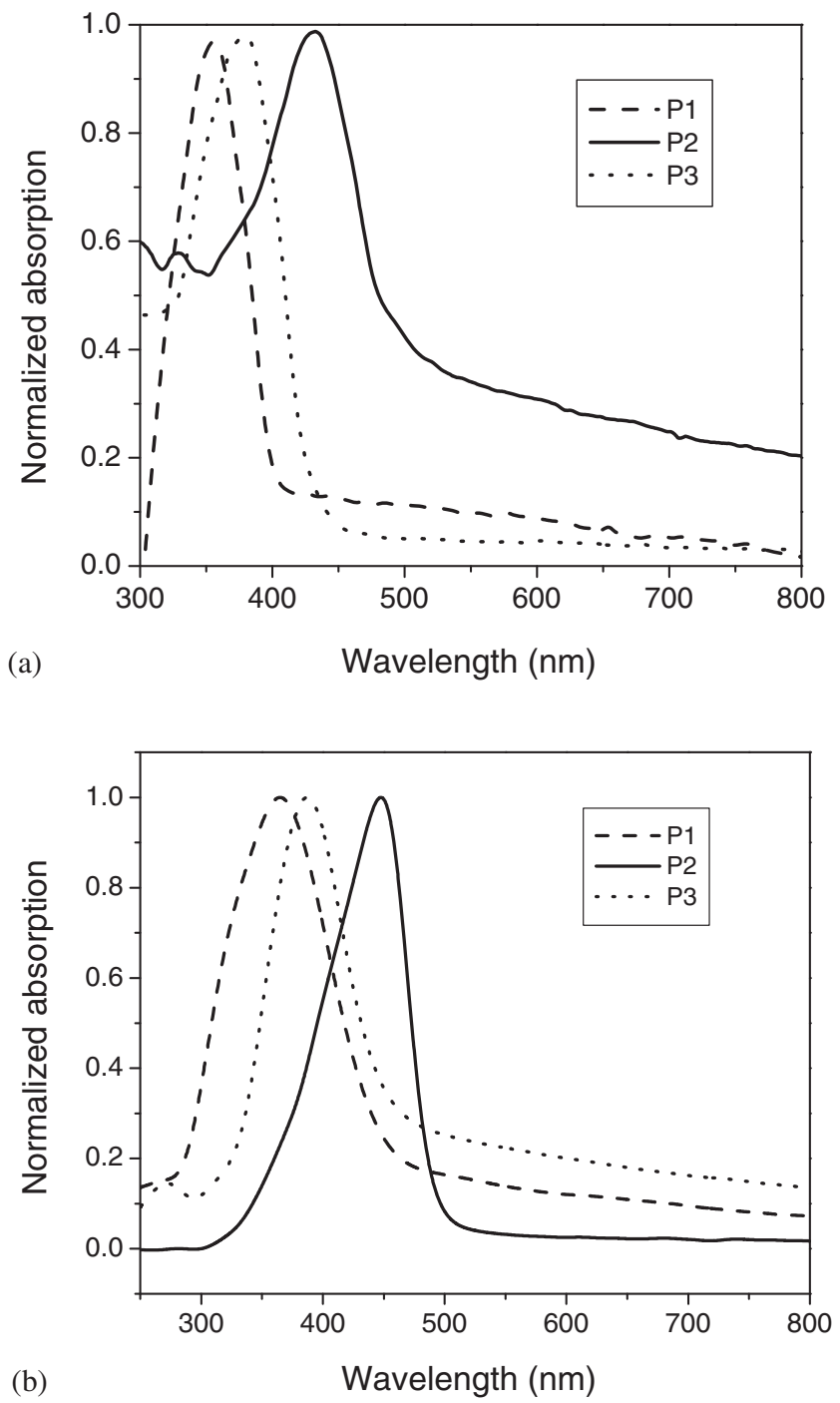

Figure 4. UV-vis absorption spectra of (a) polymer solutions in dilute $\mathrm{CHCl}_{3}$ solution and; (b) polymer films.
P2 which increases the extent of $\pi$-conjugation. Also, these vinylene linkages serve to planarize the polymer backbone by overcoming torsional interactions between rings which further extends the $\pi$-conjugation in the polymer. The polymers showed little absorption in the longer wavelength region $(500-800 \mathrm{~nm})$ which may be due to the formation of polymer aggregates. ${ }^{20}$ The optical band gap of these polymers was found to be in the range $2.51-2.76 \mathrm{eV}$. The band gap of these polymers is slightly higher when compared with those of fully conjugated polymers which could be attributed to the interruption of conjugation by non-conjugated linkers. The fluorescence emission spectra of polymers P1, P2 and $\mathbf{P 3}$ in dilute $\mathrm{CHCl}_{3}$ solution and in film form are shown in Figure 5, and the corresponding emission maxima are tabulated in Table 1. These polymers (P1, P2 and P3) emit intense bluish color. The blue shift of the spectra is a result of the conjugation confinement by the
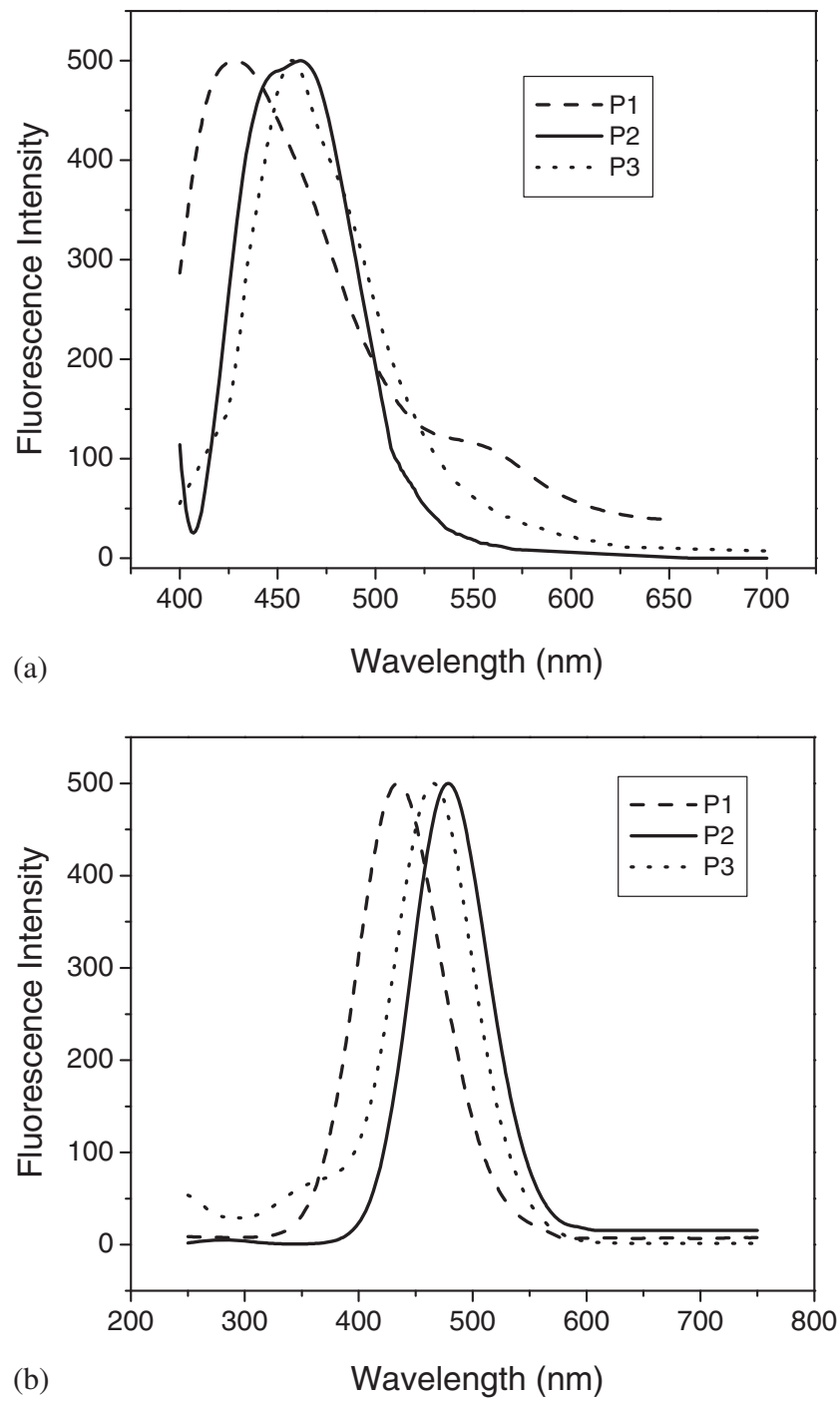

Figure 5. Fluorescence emission spectra of (a) polymer solutions in dilute $\mathrm{CHCl}_{3}$ solution and; (b) polymer films. 
introduction of non-conjugated linkers. The confinement of the effective conjugation does not allow the charge carriers to diffuse along the polymer chain, thus limiting their transport to quenching sites. ${ }^{21,22}$ A notable variation is observed in the absorption and emission behavior between $\mathbf{P 1}$ and $\mathbf{P 3}$ though the conjugation unit remains the same in these polymers. This may be due to the presence of additional conjugated unit (cyanophenylene units) in $\mathbf{P 3}$ as compared to $\mathbf{P 1}$. The conjugation length of this unit (with three phenyl rings and two cyanovinylene units) is quite significant to alter the absorption and emission behavior of the polymer.

The optical properties of the polymers were compared with those of a conjugated monomer (M) which contains oxadiazole-thiophene-oxadiazole segment (Figure 6). The conjugation length of $\mathbf{M}$ is almost the same as that of the conjugated segment in P1. The monomer showed absorption maximum in the range $355-360 \mathrm{~nm}$ and an emission maximum at $422 \mathrm{~nm}$ (Figure 7), the values match with the corresponding absorption and emission maxima respectively of $\mathbf{P 1}$. This observation further confirms the confinement of conjugation length in the polymers by the introduction of nonconjugated linkers.

\subsection{Electrochemical properties}

Cyclic voltammetric (CV) studies were used to determine redox potentials and to estimate the highest occupied

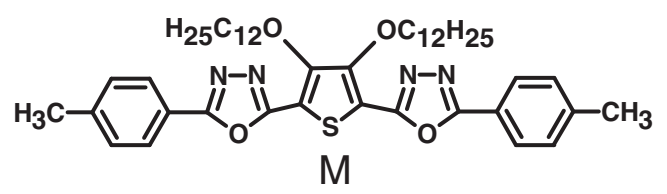

Figure 6. Structure of monomer $\mathbf{M}$.

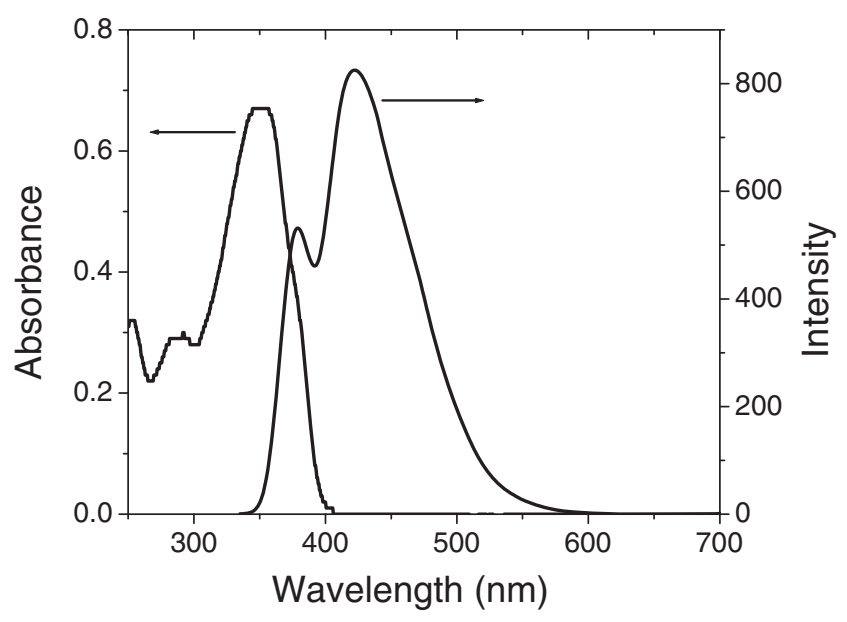

Figure 7. UV-Vis absorption and fluorescence emission spectra of monomer $(\mathbf{M})$ in solution. molecular orbital (HOMO) and lowest unoccupied molecular orbital (LUMO) energy levels of the newly synthesized polymers. Cyclic voltammograms of P1-P3 shown in Figure 8 reveal that all three polymers are both $\mathrm{p}$ - and n-dopable which could be attributed to the presence of both electron donor and electron acceptor units with an alternate D-A arrangement in the conjugated segment of the polymers. The onset oxidation and onset reduction potentials were used to estimate the HOMO and the LUMO energy levels of polymers according to the following equations, ${ }^{23-25}$

$\mathrm{E}_{\mathrm{HOMO}}=-\left[\mathrm{E}_{\text {onset }}^{\text {oxd }}+4.4 \mathrm{eV}\right]$ and $\mathrm{E}_{\mathrm{LUMO}}=-\left[\mathrm{E}_{\text {onset }}^{\text {red }}+\right.$ $4.4 \mathrm{eV}]$, where $\mathrm{E}_{\text {onset }}^{\text {oxd }}$ and $\mathrm{E}_{\text {onset }}^{\mathrm{red}}$ are the onset potentials versus standard calomel electrode (SCE) for the oxidation and reduction processes of a polymer, respectively. All the polymers showed an oxidation peak at around $1.8 \mathrm{~V}$ with a reduction peak at around $-1.7 \mathrm{~V}$. The polymers exhibit similar redox potentials and their HOMO/ LUMO energy levels also are comparable (Table 2) as the structure of the conjugated segment in these polymers is almost the same. However, an additional oxidation peak was observed at a lower potential value $(0.84 \mathrm{~V})$ for $\mathbf{P 2}$, which could be due to the oxidation of the alkoxy linkers. Similarly, polymer P1 showed a reduction peak at $-2.05 \mathrm{~V}$ due to the reduction of phenoxy linker whereas facile reduction of the cyanocontaining linker in P3 is evident by the appearance of a small reduction peak at $-1.06 \mathrm{eV}$. All three polymers (P1-P3) exhibit low-lying HOMO and LUMO levels because of the D-A structure of the conjugated segment. The electron affinity (LUMO level) of the polymers were higher than those of 2-(4-biphenyl)-5-(4tert-butylphenyl)-1,3,4-oxadiazole (PBD), ${ }^{26}$ aluminum tris(8-hydroxyquinolinate) $\left(\mathrm{Alq}_{3}\right)^{27}$ and cyano-poly(pphenylenevinylene) (CN-PPV), ${ }^{28}$ which are some of the widely used electron transporting materials. Hence, polymers P1-P3 may be considered as promising active materials in the fabrication of PLEDs. The electrochemical band gap $\left(\mathrm{E}_{\mathrm{g}}^{\mathrm{el}}\right)$ of the polymers was calculated based on the formula $\mathrm{E}_{\mathrm{g}}^{\mathrm{el}}=\mathrm{E}_{\mathrm{LUMO}}-\mathrm{E}_{\mathrm{HOMO}}$ and the values are tabulated in Table 2. Among three three polymers, similar to the results obtained in the optical studies, polymer $\mathbf{P 2}$ with higher extent of $\pi$-conjugation showed the lowest electrochemical band gap $\left(\mathrm{E}_{\mathrm{g}}^{\mathrm{el}}\right)$.

\subsection{Electroluminescent properties}

To carry out preliminary studies on electroluminescence properties of polymers, polymer light-emitting devices were fabricated with a device configuration of ITO/ $\mathrm{MoO}_{3} /$ polymer/LiF/Al. P1 and P2-based devices emitted blue light whereas P3-based device was not stable under testing (ambient) conditions and did not 
emit light at all. The presence of cyanovinylene group, which is susceptible to undergo oxidative degradation under ambient conditions may be one of the reasons for the failure of P3-based device. The current densityvoltage characteristics of polymer $\mathbf{P 2}$ is shown in Figure 9. The current density increases exponentially with the increasing forward bias voltage, which is a typical diode characteristic. The threshold voltage of $\mathbf{P 1}$ and $\mathbf{P 2}$ is 22.5 and $5.2 \mathrm{~V}$, respectively, which suggests that P2 could be a promising material for the fabrication of blue-emitting diodes. However, further studies on optimization of device configuration, device efficiency and life time are essential to consider the practical utility of these polymers.

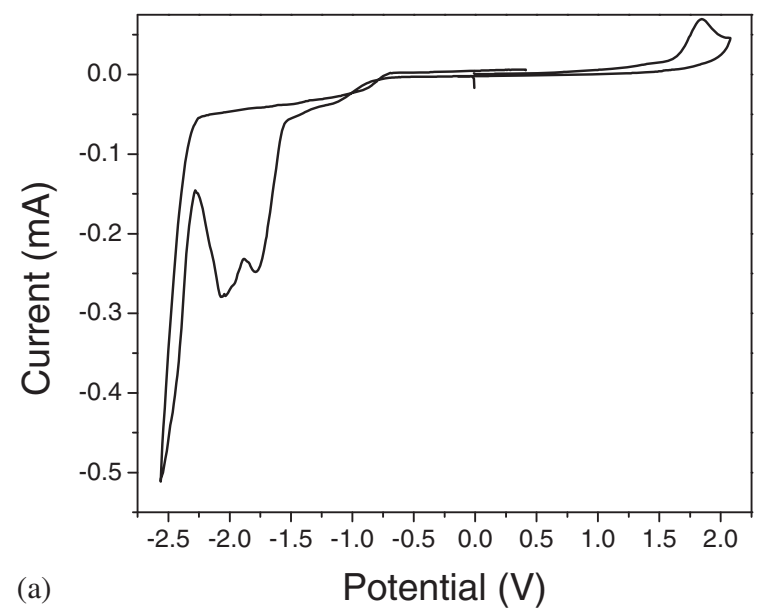

\subsection{Nonlinear optical properties}

The open aperture Z-scan data obtained from samples $\mathbf{P 1}, \mathbf{P 2}$ and P3 dissolved in chloroform are shown in Figure 10. Samples P1, P2 and P3 show linear transmittance of 82,52 and $70 \%$ respectively, at the excitation wavelength when taken in the $1 \mathrm{~mm}$ cuvette. The transmission of the samples get decreased as the input light intensity increases (intensity is maximum at $\mathrm{z}=0$ ) which signifies the strong optical limiting behavior of the polymers. Therefore, strong two-step excited state absorption will happen along with weak genuine twophoton absorption (2PA) resulting in an optical limiting phenomenon. The net effect is then known as an

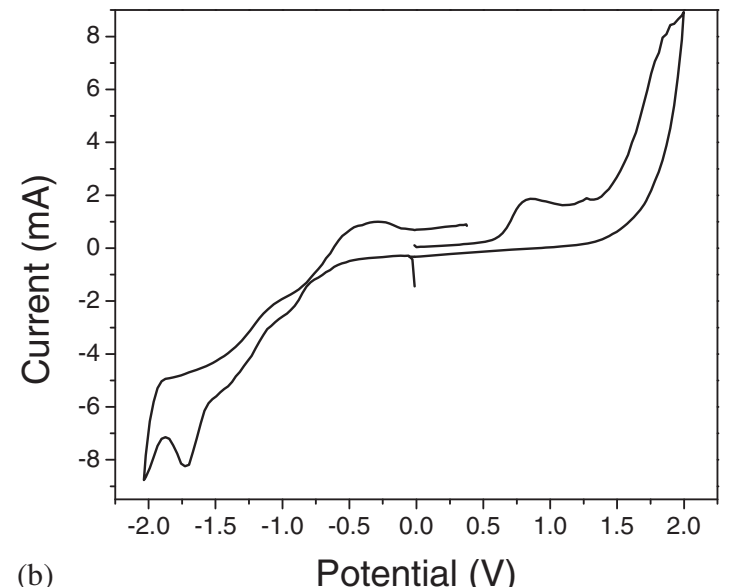

(b)

Potential (V)

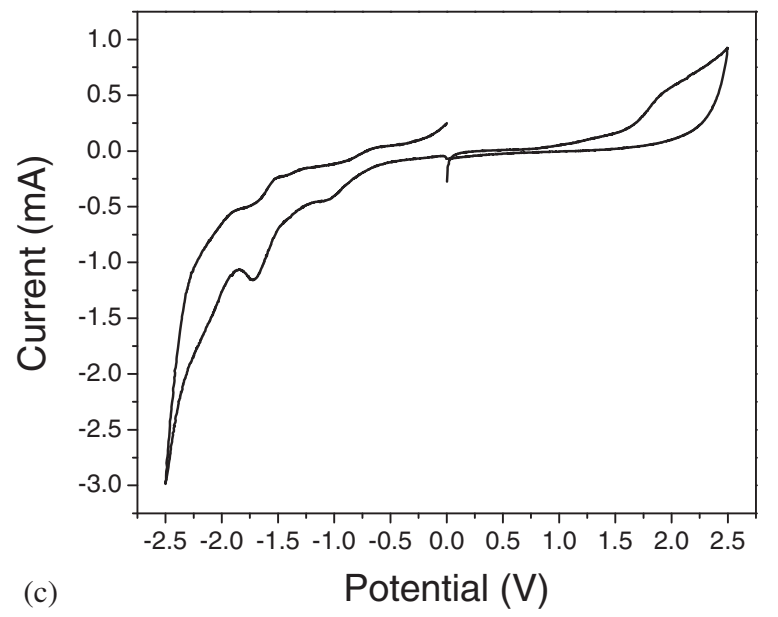

Figure 8. Cyclic voltammogram of (a) P1, (b) $\mathbf{P 2}$ and (c) $\mathbf{P 3}$ at $25 \mathrm{mV} / \mathrm{s}$ scan rate in ACN/TEAPC (0.1 M) solution.

Table 2. Electrochemical potentials and energy levels of polymers P1, P2 and P3.

\begin{tabular}{lccccccc}
\hline Polymer & $\mathrm{E}_{\text {onset }}^{\text {oxd }}$ & $\mathrm{E}_{\text {onset }}^{\text {red }}$ & $\mathrm{E}_{\text {oxd }}$ & $\mathrm{E}_{\text {red }}$ & HOMO $(\mathrm{eV})$ & $\mathrm{LUMO}(\mathrm{eV})$ & $\mathrm{E}_{\mathrm{g}}^{\mathrm{el}}(\mathrm{eV})$ \\
\hline P1 & +1.58 & -1.49 & +1.84 & -1.77 & -5.98 & -2.91 & 3.07 \\
P2 & +1.42 & -1.31 & $+0.85 /+1.89$ & -1.72 & -5.82 & -3.09 & 2.73 \\
P3 & +1.60 & -1.28 & +1.87 & $-1.72 /-1.14$ & -6.0 & -3.12 & 2.88 \\
\hline
\end{tabular}


"effective" 2PA process. It was noticed that a 2PA type process gives the best fit to the obtained experimental data. The $Z$-scan data obtained were therefore numerically fitted to the nonlinear transmission equation for a 2PA process, given by equation,

$$
\alpha(I)=\frac{\alpha_{o}}{1+\frac{I}{I_{s}}}+\beta I
$$

where, $\alpha\left(\mathrm{m}^{-1}\right)$ is the unsaturated linear absorption coefficient at the wavelength of excitation, and $I_{s}$ $\left(\mathrm{W} / \mathrm{m}^{2}\right)$ is the saturation intensity (intensity at which the linear absorption drops to half its original value). $\beta(\mathrm{m} / \mathrm{W})=\sigma \mathrm{N}$ is the excited state absorption (ESA) coefficient, where $\sigma$ is the ESA cross section and N(I) is the intensity-dependent excited state population density, $\beta$ is the effective 2PA coefficient (Table 3). For calculating the output laser intensity for a given input intensity, first we numerically evaluate the output intensity from the sample for each input intensity by solving the propagation equation,

$$
\frac{d I}{d Z^{\prime}}=-\left[\left(\frac{\alpha_{o}}{1+\frac{I}{I_{s}}}\right)+\beta I\right] I
$$

using the fourth order Runge-Kutta method. Here Z' indicates the propagation distance within the sample. Input intensities for the Gaussian laser beam for each sample position in the Z-scan are calculated from the input energy, laser pulse width and irradiation area. The normalized transmittance $\left(\mathrm{T}_{\text {norm }}\right)$ is then calculated

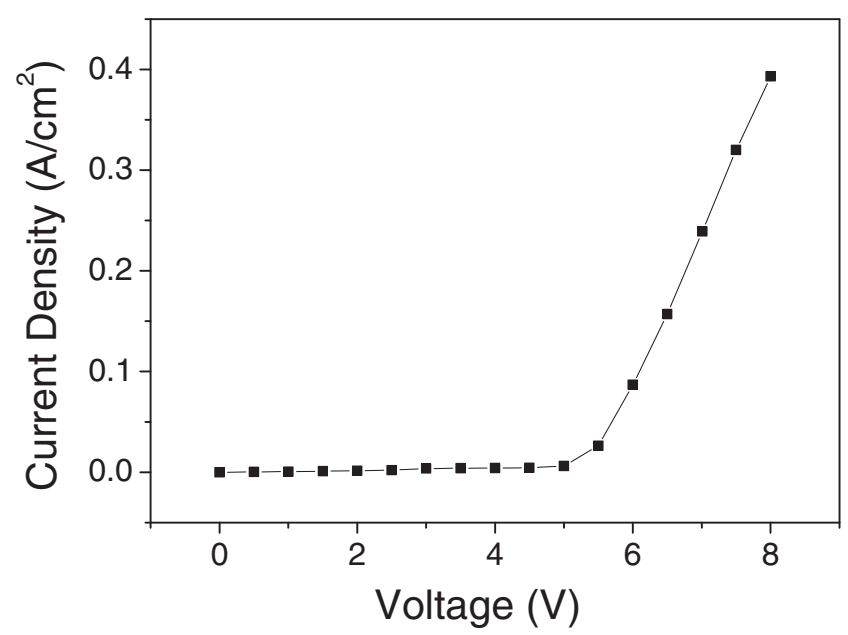

Figure 9. Current density-voltage characteristics of device ITO/MoO $3 / \mathrm{P} 2 / \mathrm{LiF} / \mathrm{Al}$.

Table 3. Numerically estimated $\beta$ value of the polymers.

\begin{tabular}{cccc}
\hline Polymer & P1 & P2 & P3 \\
\hline$\beta(\mathrm{m} / \mathrm{W})$ & $3.4 \times 10^{-11}$ & $6.5 \times 10^{-11}$ & $0.75 \times 10^{-11}$ \\
\hline
\end{tabular}

by dividing the output intensity with the input intensity and normalizing it with the linear transmittance. As seen from Figure 10, there is superior concurrence between the experimental data and numerical simulation. The numerically estimated value of $\beta$ for $\mathbf{P 1}$, $\mathbf{P 2}$ and $\mathbf{P 3}$ are $34 \times 10^{-11}, 65 \times 10^{-11}$ and $0.75 \times$ $10^{-11} \mathrm{~m} / \mathrm{W}$ respectively. Interestingly, these values are comparable with the $\beta$ values obtained for some fully conjugated D-A polymers containing thiophene and
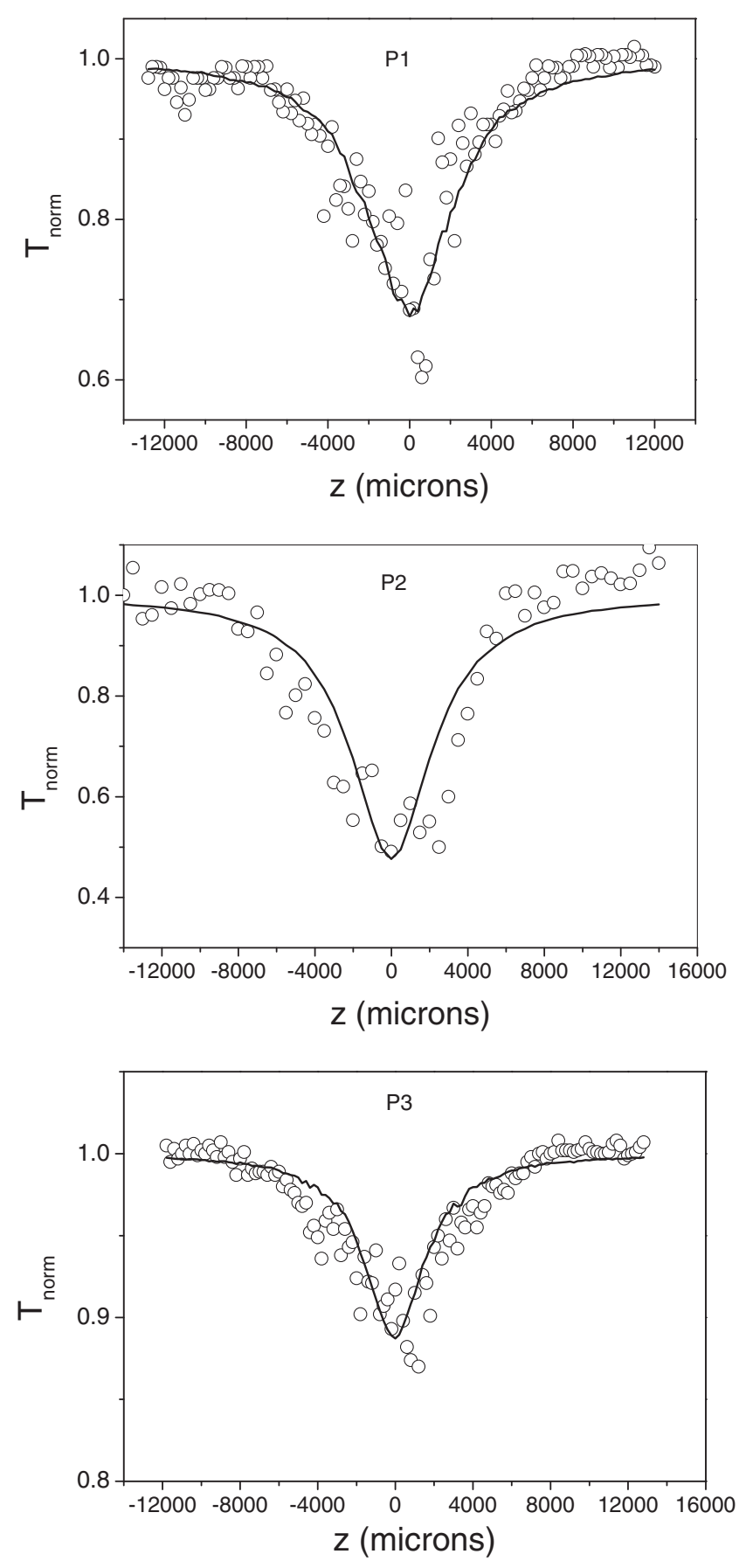

Figure 10. Open aperture Z-scan curve of polymers P1, P2 and P3. Hollow circles are data points while the solid curves are the numerical fit obtained using equation (2). 
1,3,4-oxadiazole units ${ }^{9}$ which suggests that the confinement of $\pi$-conjugation does not affect significantly the NLO properties of these D-A systems. Among P1-P3, polymer $\mathbf{P 2}$ with higher extent of $\pi$-conjugation exhibited the highest value for $\beta$. Hence these polymers are promising candidates for optical limiting applications.

\section{Conclusions}

Three D-A conjugated polymers (P1, P2 and P3) containing nonconjugated linkers and 3,4-didodecyloxythiophene unit as electron-rich moiety were synthesized through a multistep synthetic route. Thermogravimetric analysis revealed that polymer $\mathbf{P} \mathbf{2}$ containing alkoxy linker exhibit lower onset decomposition temperature when compared with that of polymers $\mathbf{P 1}$ and $\mathbf{P 2}$ which contain methyleneoxy phenyl linkers. Interruption of the $\pi$-conjugation by nonconjugated linker affects the linear optical properties of the polymers. As a result, these polymers showed slightly higher optical band gap than that of fully conjugated polymers and the emission maxima of these polymers shifted to the blue region. It is evident from the cyclic voltammetry studies that all three polymers (P1-P3) exhibit low-lying HOMO and LUMO levels because of the D-A structure of the conjugated segment. The test light-emitting device based on P2 with a device configuration of ITO/ $/ \mathrm{MoO}_{3} /$ polymer/LiF/Al, emitted blue light with a low threshold voltage of 5.2 V. Z-scan studies revealed the strong optical limiting behavior of these polymers. Though the confinement of pi conjugation affect the linear optical properties of the polymers, it did not show any significant effect on their NLO properties and their 2PA coefficient $(\beta)$ value is comparable with that of fully conjugated D-A polymers. These results reveal that the synthesized polymers are the promising materials for optoelectronic device applications.

\section{Supplementary Information}

${ }^{1} \mathrm{H}$ NMR spectra of monomer $\mathbf{3}$ and polymers P1-P3 are available at www.ias.ac.in/chemsci.

\section{Acknowledgements}

UKD thanks SERB, DST India for the financial support (Ref. No.SB/FT/CS-145/2012).

\section{References}

1. Skotheim T A and Reynolds J R 2007 In Conjugated Polymers -Theory, Synthesis, Properties and Characterization $3_{\text {rd }}$ edn. (Boca Raton: CRC Press)

2. Park S H, Cho S, Lee J K, Lee K and Heeger A J 2009 Org. Electron. 10426

3. Guo X, Baumgarten M and Müllen K 2013 Prog. Polym. Sci 381832

4. Bian L Y, Zhu E W, Tang J, Tang W H and Zhang F J 2012 Prog. Polym. Sci. 371292

5. Balan A, Gunbas G, Durmus A and Toppare L 2008 Chem. Mater. 207510

6. Zhang Z-G and Wang J 2012 J. Mater. Chem. 224178

7. Albota M, Beljonne D, Bredas J L, Ehrlich J E, Fu J Y, Heikal A A, Hess S E, Kogej T, Levin M D, Marder S R, McCord-Moughon D, Perry J W, Rockel H, Rumi M, Subramaniam G, Webb W W, Wu X L and Xu C 1998 Science $\mathbf{2 8 1} 1653$

8. Huang C, Sartin M M, Cozzuol M, Siegel N, Barlow S, Perry J W and Marder S R 2012 J. Phys. Chem. A 116 4305

9. Murali M G, Dalimba U and Sridharan K 2012 J. Mater. Sci. 478022

10. Tian B, Zerbi G, Schenk R and Mullen K 1991 J. Chem. Phys. 953191

11. Wang J and Leung L M 2013 Dyes Pigm. 99105

12. Gudeika D, Grazulevicius J V, Sini G, Bucinskas A, Jankauskas V, Miasojedovas A and Jursenas S 2014 Dyes Pigm. 10658

13. Yuan Z, Yu Z and Tan S 2006 J. Mater. Sci. 416103

14. Xia A, Yuan Z, Tan S, Zou Y, Tan Z, Yang Y and Li Y 2007 Eur. Polym. J. 431394

15. Sim J H, Kim S J, Yamada K, Yokokura S, Natori I, Natori S and Sato H 2009 Synth. Met. 15985

16. Hay M and Klavetter F L 1995 J. Am. Chem. Soc. 117 7112

17. Xu X, Zhang H, Liu X, Zhuang Q and Han Z 2010 Eur. Polym. J. 46528

18. Zhao M, Hashimoto K and Tajima K 2013 Synth. Met. 1759

19. Sheik-Bahae M, Said A A, Wei T H, Hagan D J and Van Stryland E W 1990 IEEE J. Quant. Electron. 26760

20. Nguyen T-Q, Doan V and Schwartz B J 1999 J. Chem. Phys. 1104068

21. Sun R G, Wang Y Z, Wang D K, Zheng Q B, Kyllo E M, Gustafson T L, Wang F and Epstein A J 2000 Synth. Met. 111595

22. Kyllo E M, Gustafson T L, Wang D K, Sun R G and Epstein A J 2001 Synth. Met. 116189

23. Yang C J and Jenekhe S A 1995 Macromolecules 28 1180

24. Agrawal A K and Jenekhe S A 1996 Chem. Mater. 8579

25. Leeuw D M D, Simenon M M J, Brown A R and Einerhand R E F 1997 Synth. Met. 8753

26. Pommerehne J, Vestweber H, Guss W, Mahrt R F, Bässler H, Porsch M and Daub J 1995 Adv. Mater. 7551

27. Destruel P, Jolinat P, Clergereaux R and Farenc J 1999 J. Appl. Phys. 85397

28. Bradley D D C 1993 Synth. Met. 54401 